\section{THE HURON RACE AND ITS HEAD FORM}

THE tribe of North American Indians known by the name of Hurons appears, when first brought to the knowledge of the intruding French, to have been settled in palisaded villages around Lake Simcoe, in Western Canada. They called themselves Ouandots or Wyandots. They consisted of four septs or nations ; the Attignaouentans, or Nation of the Bear, the chief member of the league, the Attignenonghaes, the Ahrendarrhonons, and the Tohotaenrats. They occupied thirty-two villages when visited by the Jesuit missionaries in 1639 . Brébeuf reckoned them in all in 1635 at 30,000 , and they were stated in the Relation of 1660 at 35,000 . The Hurons with other tribes dwelling at this time in Canada, were fully acquainted with agriculture, as Dr. Wilson shows, wholly independent of any European influences. The Hurons became known to the civilised world only in their decline, and immediately before their extirpation. They were then in alliance with the Adirondacks and other Algonquins, against their common Iroquois enemy. This latter is the name of a league of tribes often designated the Indians of the Five or of the Six Nations. This confederation of tribes during the seventeenth century was the great aggressive nationality of the American Continent, which subdued, exterminated, or incorporated the other tribes with which they came into contact. Cartier discovered Canada in 1535. Champlain explored and settled it subsequently. He visited the Huron country in 1615 , and appears to have found the whole district between the river Ottawa and Lake Simcoe to have been almost depopulated, which is to be attributed to the implacable enmity of the Iroquois. This region, "in the latter part of the seventeenth century became the scene of the indefatigable operations of a succession of missionary fathers, some of whom divided their self-denying labours between them and their Iroquois foes, and several suffered martyrdom at the hands of the savage nations whose conversion they aimed at. Minutely detailed maps and narratives of exploration and missionary labours, record the progress of discovery in the region around the Georgian Bay, and illustrate the topography of the Huron villages so accurately, that most of their sites have been identified in recent years. Dr. J. C. Taché devoted such leisure as be could command during a period of five years, prior to 1865 , to a minute exploration of the Huron country. Following in the steps of early writers whose accounts are preserved in the Relations of the Jesuit Fathers, communicated to the Provincial of the Order at Paris, from I6I I to I672, he was able to determine the sites of their principal villages, and to explore their cemeteries, abounding with implements, weapons, and numerous other archæological records of native arts and habits.

The sepulchral rites of the Hurons were of a peculiar character. Their dead were primarily exposed on raised biers, as is still done by the Cowlitz, Columbia River, and other tribes; and around them were hung implements and personal ornaments of the deceased, with the tributes of affection of the survivors. In the case of death on a journey, or on the war-path, the body was temporarily interred. But the place of sepulture was carefully noted for future transfer of the bones to the general cemetery of the tribe. At intervals of ten or twelve years the great "Feast of the Dead" was celebrated by each nation of the Huron confederacy. One of these grand ceremonies, performed at Ossosane, the chief town of the Bear nation, on Nottawasaga Bay, was witnessed by the Jesuit missionaries in 1636 . Skeletons were gathered from old scaffoldings, or disinterred from distant graves, by the relations of the deceased. The bones of those more recently dead were cleansed of the remaining flesh, and then wrapped carefully in skins, and adorned with prized

* The Huron Race and its Head Form. By Daniel Wilson, LL.D. 3 plates. decorations. The old wampum-belts, pipes, kettles, bows, arrows, axes, beads, and shells, which had been hung around the bier, or deposited in the grave, were anew gathered together, and the whole were brought to the appointed cemetery. There a great trench was dug, and carefully lined with beaver skins and other furs, and after a funeral-feast, with lamentations by the women, and orations by some of the chiefs in praise of the dead, the relics of mortality were cast into the trench, along with the funeral offerings. Only in cases of recent death were the corpses wrapped in furs and deposited entire; and then, amid the shrieks and wails of the mourners, the earth was thrown in, logs and stones piled over the cemetery, and with a closing funeral chant, the great "Feast of the Dead" was brought to a close.

Owing to the systematic practice of thus gathering together the remains of the Huron dead, one or more ossuaries were to be looked for in the vicinity of each village. Dr. Taché explored sixteen of them in all, containing from 600 to 1,200 skeletons in each. From the same depositories he also recovered numerous specimens of native art, and illustrations of the various customs of that people. From the same cemeteries, Dr. Tache selected upwards of eighty skulls, most of which with the accompanying relics he deposited in the museum of the Laval University, at Quebec. Another inquirer, Mr. John Langton, a writer "On the Early Discoveries of the French in North America," conceived the same idea of tracing the villages of the Hurons. He succeeded in tracing out the sites of fourteen villages, in many of which the remains of houses and stockades could still be recognised. He even succeeded in identifying St. Ignace, a village at which the principal chief and nearly Ioo of the Iroquois warriors fell before the Hurons were overpowered, and the miserable remnant bound to stakes to perish in the relics of their blazing settlement. St. Ignace was finally destroyed in 1649. Some few Hurons found refuge among the Petuns, Neutres, and Eries, and shared in the subsequent fate of these tribes. The fortunes of another body of the fugitives illustrate the Indian practice of adoption into another tribe. The survivors of two Huron towns opened negotiations with their Seneca foes, and were adopted into the Seneca nation. And another band, under the conduct of the Jesuit missionaries, made their way to Quebec, then subsequently settled at Lorette, on St. Charles's river, where their lineal descendants remain, their blood mingled with that of European colonists, and speaking a French patois, and where they still share in certain Indian funds distributed to them by the Canadian Government.

The admixture of blood has nearly effaced the genuine characteristics of the Hurons of Lorette, although this tribe originally does not appear to have been exposed in the same degree to the adoption of prisoners of other tribes as that of the Iroquois Confederacy. Hence the remains recovered from the ancient cemeteries of the Huron country have a special value for ethnological purposes; they are the most authentic relics of the pure Hurons. As an instance of the readiness with which the aggressive Iroquois received those of other races into their tribe, Dr. Wilson speaks of an old squaw of pure white blood, reputed to be nearly a century old, who survived till recently, if she be not still living, as a member of the Mohawk tribe, of the Bay of Quinte. Her Indian name is Ste-nah, supposed to be a contraction of Christiana, and she is described as a full-blood Sko-ha-ra, or Dutchwoman. When the author last heard of her, in 1868 , she was living with her granddaughter, the wife of a Mohawk chief.

The learned author is probably the solitary instance of a well-instructed British Craniologist being transferred to American soil, who has continued his favourite pursuit in the new field with perseverance. Dr. Daniel Wilson has given numerous and valuable proofs of his abiding taste for, and persistent investigation in, this fundamental branch of anthropological inquiry. In his compre- 
hensive "Pre-Historic Man," which has reached a second edition, he has already paid a good deal of attention to the Huron tribe, as well as to other tribes of the North American Indians, which, in fact, constitutes one great feature of value in the work.

In this volume Dr. Wilson gave a table of the measurements of thirty-seven Huron skulls "obtained from Indian graves to the north of the water-shed between Georgian Bay and Lakes Erie and Ontario." The great purpose of the construction of this table, as of so many other investigations made by the author, was to test the truth of a doctrine which had been generally reccived and was in great measure endorsed by Dr. S. G. Morton, who produced the classical "Crania Americana." This doctrine, in few words, is that the American race is almost uniform in its head characters from one end of the continent to the other, and that the American typical cranium is distinguished for its shortness. To Dr. D. Wilson's persevering researches we must allow the merit of having shown that there is much variety in native American races, and that in their skulls there is considerable diversity of length. This may be very confidently asserted, without conceding to him an agreement with his assertions respecting the long skulls among the ancient Peruvians; for he evidently mistook the deformed crania of these people for the representatives of the natural form of their heads.

In the table of the measurements of thirty-seven human skulls referred to, it was seen that their length varied much. If we exclude the "Barrie skull," No. 23, which appears to be quite aberrantly short, and it is thought has been distorted by art, we find their longitudinal diameter to vary from $7^{\circ} 9$ inches to 6.8 inches, or above an inch. The cephalic indices of these two examples, unfortunately, cannot be accurately calculated from Dr. Wilson's measurements. One of his items of measurement is "F. D." frontal diameter, which he says in this memoir "is taken from the point of junction of the frontal, parietal, and malar bones." This latter is probably an inadvertence, and should be sphenoidal bone, as the malar bone nowhere joins the frontal.

Since this table was constructed, thanks to the efforts of Dr. Taché and others, Dr. Wilson has had the opportunity of measuring many more Huron skulls. He now says : "The sight of upwards of seventy skulls, all derived from the cemeteries of a single tribe or nation, is a peculiarly interesting study to the ethnologist. But to one at all impressed with the uniform persistency of a specific ethnical type, the result is far from satisfactory." They are seen to vary materially, and especially in length. The skulls of women present a decided projection of the occiput, and here we may be permitted to allude to Dr. Wilson's plates. The first, which gives shaded profile views of the calvaria of a Huron man and woman, is excellent and very characteristic. Plate II. is lettered, "Long Huron skull, male." It is often very difficuit to determine positively the sex in crania, but in this example it seems doubtful whether the plate does not exhibit the calvarium of a woman. We incline to think that it does. The long oval, vertical view is quite apparent and unquestionable. Plate III. is an undoubted instance of a "Long Huron skull, male."

Dr. Wilson, after attesting the great range of diversities in the Huron skulls he has seen, concludes in these noticeable terms: "But the specialties of the whole, in their front aspect, suggest a greater uniformity in their physiognomy than in cranial conformation. The nose is in most cases large and prominent; the superciliary ridges in the males are strongly developed; and a common ethnical character may be traced in the full-face as a whole, including the massive broad cheek-bones and superior maxilla; as well as in the indications in the greater number of a tendency towards a pointed apex, or meeting of the parietal bones at an angle at the sagittal suture." Perhaps this is as much as anyone can reasonably expect, even when divergences are to be acknowledged in the proper calvarial form. And it is difficult to conceive that these divergences are so utter and so puzzling as to prevent our seeing any constancy among them.

Dr. Wilson, in showing that some tribes of American Indians are characterised by long or dolichocephalic heads, still admits that other tribes have short or brachycephalic heads. This must be conceded, as well as that Morton's generalisation was too comprehensive and too literal. Former sweeping conclusions as to dolichocephaly and brachycephaly cannot now be sustained. It was long since seen that among the crania of any extended race of people, as the ancient Britons, there is much variation as to length, indeed that a scale might be exhibited from the shortest to the longest, in which the numerous intermediate lengths intervene to fill up the ascending degrees of the range. This truth is now more than ever apparent, since the elaborate researches among the skulls of Italian races by the distinguished anatomist, Prof. Luigi Calori, of Bologna. He has conclusively shown that there is much more dolichocephaly among the races of Italy than was previously known.

Much of the difficulty that craniologists have encountered in the study of the head-forms of different races, has had its foundation in the too rigid rules which they have assumed these forms to observe. Dr. Wilson's labours have served well to illustrate this point in reference to the American races. Were this the proper place, it would be easy to point to examples of the futile labours which have resulted from these self-imposed rules. How many learned controversies have been entertained to determine the race of a man whose only existing relic was his lower jaw? On finding that such rules cannot be fixed and defined in so absolute a manner, it has often been the case that other inquirers have lost confidence in craniology itself. This is a transition from one extreme to another. More moderate expectations from the doctrine of skull forms would have prevented confidence in their value from being so often shaken. Larger views must be taken, but these are quite compatible with our knowledge, without any necessary leaning to the meanderings of the evolutionary hypotheses alluded to by our author.

\section{CONDUCTIVITY OF MERCURY}

$\mathrm{T}^{\mathrm{T}}$ was shown in a previous article * that solar intensity cannot be accurately ascertained by the thermoheliometer employed by Père Secchi, owing, among other causes, to the imperfect conductivity of the mercury in the bulb exposed to the sun. Meteorologists, however, do not generally accept the assumption that the conducting power of mercury is so imperfect as to affect materially the correctness of the indication of mercurial thermometers, Deschanel being quoted in support of the opinion that mercury is not an imperfect conductor. We are reminded that Prof. Everett, in a recent translation of the works of the author mentioned, assumed that the conductivity of quicksilver in the bulb of a thermometer is the same as a vessel "with thin metallic sides containing water which is stirred" (see Prof. Everett's translation of "Deschanel's Natural Philosophy," Part II., pp. 245-387). The subject is so intimately connected with the determination of solar temperature and solar energy, that it has become indispensable to settle the question by some thorough practical test. Accordingly an apparatus, represented by the following illustration (Fig. I, p. 266) has been constructed by the writer, to ascertain the conductivity of mercury. Before entering on a description, it will be instructive to point out that the heat communicated to the bulb of a thermometer by solar radiation is transmitted to its contents chiefly by convection, hence that the altitude of the sun during the observation influences the accuracy of the * Nature, vol, v. pp. 344-347. 